\title{
GUIANA FRANCESA, UM TERRITÓRIO EUROPEU E CARIBENHO NO CAMINHO DA SUL-AMERICANIZAÇÃO?
}

\author{
LA GUYANE FRANÇAISE, UN TERRITOIRE EUROPÉEN ET \\ CARIBÉEN EN VOIE DE SUD-AMÉRICANISATION?
}

\author{
FRENCH GUYANA, AN EUROPEAN AND CARIBBEAN TERRITORY \\ IN PROCESS OF SOUTH-AMERICANIZATION?
}

\author{
Stéphane Granger \\ Doutorando no Instituto dos Altos Estudos da América Latina (IHEAL), Paris 3. \\ granger.stephane@orange.fr
}

\section{Resumo}

A Guiana francesa, território francês da América do sul, durante muito tempo foi marginalizada pelos vizinhos sul-americanos por causa de uma situação considerada "colonial", e pelos laços e a história mais parece um território caribenho. Mas, já alvo de amplos fluxos migratórios brasileiros e cada vez mais peruanos, tornou-se agora atrativa como porta de entrada da União Européia para os países sulamericanos, que mais que a França perceberam esta situação de interface entre América do sul e Europa, simbolizada pela construção de uma ponte na fronteira Guiana francesa-Brasil e a busca de acordos bilaterais. Porém, estatuto político, diferenças socio-econômicas, lógicas protecionistas e mentalidades ainda estão dificultando uma inserção maior do departamento francês no seu ambiante geográfico, o qual também iniciou um processo de integração que pode deixar a Guiana de fora.

Palavras-chave: Guiana francesa, Brasil, América do sul, migrações internacionais; perifericidade, integração regional. 


\title{
Résumé
}

La Guyane française, territoire français en Amérique du sud, fut longtemps marginalisée par ses voisins sud-américains à cause de sa situation considérée «coloniale », et de par ses liens et son histoire parait davantage un territoire caribéen. Mais, depuis longtemps déjà objet d'intenses flux migratoires en provenance du Brésil et de plus en plus du Pérou, elle devient maintenant attractive comme porte d'entrée de l'Union Européenne pour des pays sud-américains qui plus que la France ont perçu cette situation d'interface, symbolisée par la construction d'un pont à la frontière de la Guyane et du Brésil et la signature d'accords bilatéraux. Cependant, statut politique, écarts socio-économiques, logiques protectionnistes et mentalités freinent encore une meilleure insertion du département français dans son environnement géographique, lequel connaît également un processus d'intégration qui pourrait laisser la Guyane à l'écart.

Mots-Clés: Guyane Française, Brésil, Amérique du Sud, les migrations internationales; périphérie, l'intégration régionale.

\begin{abstract}
French Guiana, a french territory in South America, was marginalized for a long time by his South American neighbours because of its situation considered "colonial", and due to its links and its history appears more a Caribbean territory. But, for a long time already object of intense migratory streams from Brazil and more and more Peru, it becomes now attractive as front door of the European Union for South American countries which more than France perceived this situation of interface, symbolized by the construction of a bridge on the border of Guyana and Brazil, and signature of bilateral agreements. However, political situation, socioeconomic distances, protectionist logics and mentalities slow down another better insertion of the French department in its geographical environment, which also knows a process of integration which could leave Guyana aside.
\end{abstract}

Key-Words: French Guiana, Brazil, South America, international migration; remoteness, regional integration.

\section{Introdução}

Um dos efeitos do atual fenómeno de globalização que afeta o mundo é que pode condenar a curto ou longo prazo os países demasiados isolados e afastados dos grandes eixos de intercâmbios econômicos, provocando assim recomposições 
territoriais como as integrações continentais, do tipo $\mathrm{ALCAN}^{1}$, União Européia ou Mercosul.

Um caso interessante é o da Guiana francesa, território francês e politicamente europeu encravado na América do sul, entre países com os quais sempre manteve fracos laços econômicos e políticos. De fato, por muito tempo a Guiana francesa virou as costas, por motivos históricos e culturais, ao resto do continente sul-americano, que também a marginalizou por ser um território ainda europeu. Mas hoje, esta mesma situação européia torna-a atrativa para os outros países da região : as autoridades políticas e econômicas estão agora descobrindo as possibilidades desta espantosa situação no méio da União Européia, da CARICOM² e do Mercosul. Foi no entanto com atividades ilícitas que a Guiana francesa começou a integrar-se no sub-continente sul-americano, iniciando o que poderia caracterizar-se como o processo de "continentalização" de uma terra virada pelo oceano atlântico. Mas os desequilíbrios regionais e as realidades geopolíticas e econômicas ainda estão bloqueando essa evolução.

\section{Um "Caribe europeu"}

Em julho de 2006, vários estudiantes franco-guianenses participaram de uma viagem cultural na Amazônia com outros jovens provenientes de todos os países do $\mathrm{OTCA}^{3}$, dentro de um projeto científico e pan-amazônico que para a primeira vez integrava a Guiana francesa. Este terrítório via-se assim reconhecido como amazônico depois de anos, senão séculos de ostracismo. Pois, última parte ainda não soberana da América do sul, conhece uma estranha situação jurídica e política: geograficamente situado no continente sul-americano, é no entanto historicamente e culturalmente considerado como caribenho, mas também é departamento (distrito) da República francesa, e portanto da União Européia. Situada na costa setentrional da América do sul, Guiana francesa tal como Suriname e República da Guiana realmente mais parece um território caribenho do que sul-americano: isolada do

\footnotetext{
'Área de Livre Comércio da América do Norte, NAFTA em inglês.

${ }^{2}$ Mercado comum do Caribe, incluindo as ilhas membros do Commonwealth, o Suriname e Haiti.

${ }^{3}$ Organização do Tratado de Cooperação Amazônica.
} 
resto do continente pela floresta amazônica e o estatuto europeu, essencialmente povoada na faixa atlântica, falando línguas, francês e dialeto crioulo, também presentes nas Antilhas e na Europa e não nas outras partes da América do sul, com uma cultura e uma arquitectura parecidas às das Antilhas francesas, pertence incontestavelmente à área caribenha, da qual muito tempo constituiu com suas vizinhas do planalto das Guianas uma extensão protetora para as potências coloniais da Europa ocidental. Representa aliás a França na Associação dos Estados do Caribe com a Martinica e a ilha da Guadalupe, e hospedou em 2005 a cúpula internacional sobre a situação do Haiti.

A explicação é que as Guianas tinham sido atribuídas aos espanhóis pelo tratado de Tordesilhas em 1494, mas estes desprezaram-nas por serem menos interessantes e hospitaleiras do que Peru ou México. Franceses, holandeses e ingleses aproveitaram para se estabelecer no continente sul-americano do qual tinham sido excluídos pela arbitragem papal, e assim alargar e proteger seus domínios caribenhos. Mas rapidamente foram limitados pela presença da floresta amazônica e a vizinhança das potências ibéricas, "legítimas" detentoras do Novo Mundo.

Desde o século XVII a presença das três pequenas Guianas assim constitue uma anomalia dentro deste sub-continente ao qual estão virando as costas. Ainda mais, não foram implicadas no grande movimento emancipador das colônias espanholas e portuguesas da primeira metade do século XIX, e só recentemente deixaram a tutela européia: o Reino Unido acordou a independência à Guiana inglesa em 1966, e os Países-Baixos à Guiana holandesa também chamada de Suriname em 1975. A Guiana francesa pelo contrário tinha resforçado sua afiliação à metrópole francesa, de colônia sendo transformada em 1946 em departamento francês do ultra-mar, desfrutando assim de total igualdade jurídica com o resto da França. Desde que o Belize se tornou independente em 1981, a Guiana francesa é o último território continental americano ainda pertencendo a uma potência européia, estatuto que divide aliás com algumas ilhas do Caribe ainda hoje possessões holandesas, inglesas ou francesas...

Após as independências, as Guianas conservaram laços privilegiados com as 
ex-metrópoles, as irmãs antilhesas e o mundo caribenho insular, desprezando ligações com o resto da América do sul. Guiana ex-inglesa e Suriname, convidadas com os demais países de ecosistema amazônico por um Brasil desejando integrar uma Amazônia cobiçada, assinaram em 1978 o Tratado de Cooperação Amazônico (OTCA), mas a Guiana francesa ficou recusada por causa da sua "situação colonial" que teria implicado a participação da França, potência européia. Mas essas Guianas independentes preferiram depois assumir uma orientação nitidamente caribenha ao integrar os países $\mathrm{ACP}^{4}$, instituídos aliás em 1975 em Georgetown, capital da Guiana, depois a Associação dos Estados Caribenhos (AEC) em 1994 e enfim, em 1995, a CARICOM, cuja sede também fica em Georgetown.

De fato excluída dos intercâmbios e redes econômicos regionais e isolada dentro da região, a Guiana francesa via-se integrada como departamento francês na União Européia: este estatuto tal como os custos elevados de salários e produção que decorrem disso fazem que, fora do petróleo proveniente da Trindade, o essencial dos intercâmbios econômicos faz-se com a França, a União Européia e as Antilhas francesas. Guiana francesa assim é muito isolada continentalmente: só uma estrada ligando-a ao Suriname acessível por uma lancha, e em direção ao Brasil uma estrada recente, mas com a abertura da ponte prevista para 2010 só se pode por enquanto atravessar o rio Oiapoque, que faz fronteira, por barcos pequenos ou catraias, e os veículos por uma lancha cara e não oficial. As ligações aéreas também são difíceis, não existem mais entre Guiana francesa e Suriname apesar das tentativas da Air France. Com o Brasil, a Air-Caraïbes acaba de abandonar a ligação diária CaienaBelém, só sobra agora uma única companhia, brasileira, ligando três vezes por semana Caiena a Belém e Fortaleza...

Guiana francesa portanto é uma região européia dentro da América do sul: "porto espacial" da Europa com a presença do Centro espacial europeu em Kourou, conhece uma situação socio-econômica mais favorável do que os países vizinhos graças à redistribuição nacional da renda na França. Mas as taxas elevadas de fecundidade e mortalidade infantil mais lembram a América do sul do que a Europa.

4 África-Caribe-Pacífico : grupo de países que assinaram acordos econômicos privilegiados com a União Européia. 
Por isso recebe verbas especiais da União Européia por ser uma das suas regiões mais pobres e afastadas.

Só que essa verba, fazendo dos departamentos franceses da América os territórios mais ricos do Caribe e da América do sul, aumenta o lado artificial da prosperidade guianense como a distância de equipamento e de padrão de vida com os países vizinhos: custos, preços e salários são entre quatro e dez vezes superiores aos do Brasil e do Suriname, o que dificulta a cooperação econômica. Mas paradoxalmente é essa distância devida à afiliação européia que está agora permitindo uma inserção melhor da Guiana dentro do sub-continente.

\section{Uma pressão migratória caribenha e amazônica}

Guiana francesa assim constitue uma verdadeira ilha européia no méio de um oceano de pobreza, e por isso está atraíndo muitos migrantes oriundos dos países próximos. Às centenas de colombianos e principalmente de brasileiros que vieram no começo dos anos sessenta para a construção da base espacial (esses últimos consituíndo agora $10 \%$ da população), acrescentaram-se mais ou menos 10.000 surinameses fugindo da guerra civil no final dos anos 80 , e milhares de haitianos, agora a comunidade mais numerosa, dominicanos e guianenses de Georgetown. A população da Guiana francesa é oficialmente composta por $40 \%$ de estrangeiros, muito mais na realidade, e mais da metade dos partos devem-se a mulheres estrangeiras que conservaram os comportamentos demográficos dos países de origem, onde a fecundidade é mais elevada. Esses imigrantes, pela facilidade de chegar na Guiana francesa, passando pelo Suriname ou o Brasil, estão mostrando a seus habitantes, que frequentemente se esqueceram desse fato, que ela é mesmo sulamericana.

A Guiana francesa, pela imensidão vazia, a porosidade de suas fronteiras e o mercado permitido pelo alto padrão de vida, também é uma peça-chave para o tráfico de droga vindo da Colômbia via o Suriname. Este território ainda não dominado também provoca a cobiça de milhares de garimpeiros no centro e no sul, que criam lá verdadeiras aglomerações informais equipadas de bares e lojas... Tal 
fenómeno também se encontra no Suriname, na Guiana, Venezuela e Colômbia, mostrando o lado teórico da soberania desses países na Amazônia, e o aspecto virtual das fronteiras. Também se fala de uma delinquência de tipo sul-americano na Guiana francesa, pois a criminalidade devida aos clandestinos lembra pelo tipo e a violência a do Brasil ou da Colômbia.

Além disso, como símbolo da crescente "continentalização" dessas migrações, a Guiana francesa recebe desde alguns anos uma migração bastante importante de peruanos, que passaram por Iquitos, Manaus, o Amapá e agora o Suriname.

Com efeito, Suriname é a porta de entrada das migrações caribenhas (haitianas e dominicanas) dirigindo-se para a Guiana francesa, e até brasileiros e peruanos estão agora usando esse caminho: este país pouco vigiado também é pouco exigente em relação aos vistos, pois não é o país de destino mas sim um país de trânsito para a Guiana francesa. Assim como o norte da Amazônia, Guiana francesa é um prolongamento imprevisto das frentes pioneiras e auríferas brasileiras. O forte aumento de brasileiros também se deve à recente construção da estrada de Caiena ao Brasil, que facilita os fluxos em direção a Caiena, mas onde os candidatos à migração são apanhados mais facilmente (passavam antes pela floresta ou o mar).

Afinal, a Guiana francesa se integrou ao continente sul-americano em primeiro com atividades ilícitas (droga, contrabando, garimpo e imigração clandestina). Conscientes desse fato e desejando controlá-lo, os responsáveis políticos franco-guianenses e amapaenses aproveitaram as novas leis estatutárias (leis de decentralização na França em 1982, Amapá elevado a estado em 1988) para se aproximar dentro de acordos de cooperação transfronteiriça, uns na esperança de um desenvolvimento do Amapá sufocando a emigração em direção à Guiana, outros esperando o fim do encravamento geográfico e o acesso a novos mercados de consumo. A Guiana francesa até que enfim assumia sua geografia.

\section{A difícil inserção de uma região européia na América do sul}


Esses acordos de cooperação entre Guiana francesa e Amapá, assinados em 1996, foram impulsos pelo encontro em 1997 dos presidentes francês e brasileiro Jacques Chirac e Fernando Henrique Cardoso em Saint-Georges, na fronteira da Guiana com Brasil. Permitiram rapidamente a multiplicação dos intercâmbios científicos, culturais, escolários e esportivos. Símbolo supremo, os dois presidentes francês e brasileiro decidiram a construção de uma ponte ligando Guiana francesa ao Brasil, prevista para 2010, com verba brasileira, francesa e européia. Essa ponte também ligará, de fato e simbolicamente, França ao Brasil e União Européia ao Mercosul, além de permitir a abertura do norte do Brasil ao Caribe.

Essa integração crescente deve-se principalmente ao Brasil, que mais que a França percebeu o interesse e a originalidade daquela região na sua estrategia de liderança regional e continental. Afinal, a Guiana francesa constitue um fraco mercado de consumo com seus 200.000 habitantes, mas é a porta de entrada da União Européia. Por isso Brasil acorda uma importância extrema a esse projeto de ponte, que permitirá mais que uma ligação terrestre entre Guiana francesa e Amapá: também espera integrar seus estados do norte encravados entre as Guianas (o Amapá é o único estado brasileiro ainda separado por via terrestre do resto do país, pelo rio Amazonas), ligando-os à porção caribenha do continente e à CARICOM. Vale também a pena lembrar que com 730 kilómetros a fronteira guiano-brasileira é a maior da França... Brasil tornando-se assim um dos vizinhos maiores da União Européia!

Infelizmente o projeto (brasileiro) de ligação aérea entre Caiena e Manaus, que teria feito da primeira uma verdadeira porta de entrada européia no continente, e aproximado a segunda do mercado europeu, ainda não se concretizou por motivos têcnicos e econômicos.

Assim mais conhecida entre os brasileiros do norte, a Guiana francesa encontra-se cada ano oficialmente convidada em eventos regionais como o Salão do livro amazônico de Belém ou a Feira industrial de Manaus, enquanto os responsáveis políticos e econômicos guianenses tentam estabelecer relações com estados brasileiros mais dinámicos e cheios de oportunidades como Amazonas, Pará ou Ceará. 
O paradoxo agora é que a afiliação européia da Guiana francesa está tornando-a atrativa para os outros países da região, depois de tê-la afastada deles. É o que mostrou, em 2004, a aceitação dos países integrantes da OTCA da presença da Guiana como membro observador, através da França. No começo havia essa mesma OTCA em 1978 excluída a Guiana francesa como "anomalia colonial" devido a seu estatuto de território francês. Mas os tempos estão mudando, e agora sua parceria se procura: com respostas científicas européias (Instituto Pasteur, IRD ${ }^{5}, \mathrm{CIRAD}^{6}$ ) a problemas comuns como a luta contra alguns parasitas ou doenças tal a dengue ou a malária, com orçamentos e competências que nem sempre se encontram nos outros países amazônicos, Guiana francesa tem uma experiência da qual os países vizinhos gostariam de desfrutar. Também esperam assim aproximar-se da União Européia como alternativa à demasiada forte influência estados-unidense, e confiam por isso na Guiana apesar de sua situação marginal em relação à Europa. Além disso, a Guiana francesa por sua situação geográfica não podia mais ficar fora dos projetos de harmonização das políticas amazônicas, sejam elas ambientais ou até policiais, num continente em pleno processo de integração, e onde os problemas ultrapassam fronteiras geralmente artificiais. Era portanto difícil à Guiana francesa escapar deste processo de continentalização da Amazônia e da América do sul. Mas, também por causa deste estatuto europeu, não poderá participar dos votos dentro da OTCA.

Os limites estatutários porém fazem que os países da OTCA negociam diretamente com a França, contornando a Guiana francesa que para eles mais parece uma extensão geográfica da França no continente sul-americano do que um território com sua personalidade própria, apesar dos esforços das autoridades francoguianenses para afirmar-se em relação ao estado francês.

Economicamente, a cooperação econômica não teve muitos êxitos: poucas mercadorias atravessam legalmente a fronteira, os produtos consumidos na Guiana na sua imensa maioria provêm da União Européia, inclusive os sucos de frutas tropicais! A política de cooperação não superou as demasiadas altas diferenças de custo e as lógicas protecionistas dos grandes conjuntos politico-econômicos, União Européia e Mercosul, que a separam do seu ambiente geográfico.

\footnotetext{
${ }^{5}$ Instituto francês de pesquisa para o desenvolvimento.

${ }^{6}$ Equivalente ao EMBRAPA no Brasil.
} 
Por fim, a Comunidade Sul-Americana das Nações (CSAN) na sua última cúpula acaba de exclui-la, e só ela, do projeto de abolição da obrigação do passaporte e do visto entre países sul-americanos: a reciprocidade teria sido impossível por causa dos fluxos migratórios intensos em direção à Guiana, e da nacionalidade francesa dos franco-guianenses. O processo de integração sulamericana da Guiana aí encontra seus limites, por causa do mesmo fato que tinha permitido seu começo: a afiliação francesa e européia. Ainda é mais fácil para um franco-guianense como qualquer europeu morar e trabalhar na Alemanha ou no Reino Unido do que no Brasil ou no Suriname, também é mais fácil e mais barato para um sul-americano viajar em Paris do que em Caiena. Trata-se das consequências da integração européia, como também da fraqueza das relações entre Caiena e os demais países da região que resulta dessa situação.

A Guiana francesa encontra-se assim ao cruzamento de vários rumos e conjuntos político-econômicos: União Européia, AEC, Mercosul, CARICOM, OTCA, CSAN... Os imigrantes foram os pioneiros de uma integração progressiva mas limitada da Guiana francesa no seu ambiente amazônico e portanto sulamericano, provocando um começo de re-territorialização graças à conscientização recíproca das vantagens da situação de território europeu na América do sul. Num mundo cada vez mais globalizado, essa terra muito tempo excluída pela situãçao marginal em relação à França como à América do sul, também terra de exclusão com o famoso presídio extinto em 1946, poderia tornar-se uma interface capital para a União Européia. Com efeito, os alargamentos sucessíveis da União, em direção a países do Leste europeu ainda mais pobres, estão agora diminuindo seu peso como o da França e reduzindo o tamanho das verbas comunitárias.

Mas apesar da famosa piada do presidente brasileiro Luis Inácio Lula da Silva, para quem a França graças à ponte do rio Oiapoque daqui a pouco fará parte do Mercosul, a Guiana francesa por causa do seu estatuto, das fracas perspectivas de independência e da riqueza relativa que a caracteriza, por muito tempo ainda ficará como um enclave, uma região européia na América do sul mais do que uma verdadeira região sul-americana. 


\section{Referências Bibliográficas}

ANDRADE Manuel Correia de, 1989, Geopolítica do Brasil, Ática.

BATAILLON Claude, DELER Jean-Paul, THERY Hervé, 1991, Géographie universelle parte 3: Amérique latine, Belin, coleção Reclus.

BLANQUER Jean-Michel, 2005, «Les Guyanes et les Amériques entre continentalisation et «océanisation», Etudes de la documentation française, Amérique latine.

CALMONT André, 2006, "Immigration et développement en Guyane depuis la départementalisation », in Mam-Lam-Fouck Serge (coord.), L'histoire de la Guyane depuis les civilisations amérindiennes, Ibis Rouge Editions.

CAVALCANTI Kléster, 1998, « Asfalto na selva », Veja, 30 de setembro de 1998.

GRANGER Stéphane, 2001, « Coopération régionale », in Barret Jacques (coord.), Atlas illustré de la Guyane, IRD.

- 2007, « La Guyane, une région ultrapériphérique en quête d'intégration », in Mam-Lam-Fouck Serge (coord.) : Comprendre la Guyane d'aujourd'hui, Ibis Rouge Editions.

- 2007, « Guyane et Surinam à l'intersection des migrations caraïbes et sud-américaines », Terres d'Amériques $\mathrm{n}^{\circ}$ 6: «Dynamiques migratoires de la Caraïbe », Karthala.

INSEE 7 , 2004, Panorama de l'espace caraïbe, INSEE Antilles-Guyane. - 2006, Atlas des populations immigrées en Guyane, INSEE Antilles-Guyane.

LESSA Antônio Carlos Moraes, 2000, A parceria bloqueada: as relações entre França e Brasil, 1945-2000. Tese de história, Universidade de Brasília.

${ }^{7}$ Instituto francês das Estatísticas e dos Estudos econômicos. 
LEZY Emmanuel, 2000, Guyane-Guyanes, Belin.

MATTOS Carlos de Meira, 1980, Uma geopolítica pan-amazônica, José Olýmpio.

OLIC Nélson Bacic, 1997, Geopolítica da América latina, Editora Moderna.

Traduções das lendas dos esquemas em francês

Esquema $\mathrm{n}^{\circ} 1$ :

1. Ligações terrestres

2. Estrada nã asfaltada

3. Ligações aéreas

4. Ligações aéreas projetadas

Esquema $n^{\circ} 2$ :

1. Floresta amazônica

2. Garimpos clandestinos

3. Circuito das drogas

4. Fluxos migratórios

5. Frentes pioneiras

6. Pressão às fronteiras

Recebido para publicação em maio de 2008 Aprovado para publicação em junho de 2008 